Georgia State University

ScholarWorks @ Georgia State University

\title{
A social network approach to examine K-12 educational leaders' influence on information diffusion on Twitter
}

Yinying Wang

Georgia State University, ywang103@gsu.edu

Nicholas Sauers

Georgia State University, nsauers@gsu.edu

Jayson W. Richardson

San Diego State University, jayson.richardson@uky.edu

Follow this and additional works at: https://scholarworks.gsu.edu/eps_facpub

Part of the Education Commons, and the Education Policy Commons

\section{Recommended Citation}

Wang, Y., Sauers, N., \& Richardson, J. (2016). A social network approach to examine K-12 educational leaders' influence on information diffusion on Twitter. Journal of School Leadership, 26(3), 495-522.

This Article is brought to you for free and open access by the Department of Educational Policy Studies at ScholarWorks @ Georgia State University. It has been accepted for inclusion in Educational Policy Studies Faculty Publications by an authorized administrator of ScholarWorks @ Georgia State University. For more information, please contact scholarworks@gsu.edu. 


\title{
A Social Network Approach to Examine K-12 Educational Leaders' Influence on Information Diffusion on Twitter
}

\begin{abstract}
This study investigated the relationship between the leader's gender, leadership position, Twitter use, and influence on information diffusion in the communication network on Twitter. We collected the 30,200 latest tweets of 151 active Twitter users who held educational leadership positions. Results of social network analysis and multiple regression analyses suggest a gender inequality in the leader's influence on information diffusion in the network. Findings also indicate no significant relationship between leadership position (district vs. building) and a leader's influence in the network. Moreover, Twitter following was positively associated with the leader's influence in the network, whereas the number of followers, weekly tweets, and the time of Twitter account creation did not predict the leader's influence. Practical implications on how leaders use Twitter to disseminate information are discussed.
\end{abstract}

KEY WORDS: Communication, Educational Leadership, Social Network Analysis, Diffusion of Innovation, Educational Technology Leadership

Twitter, as an emerging means of communication, accentuates the potential for individuals and organizations to disseminate information without mass media (Gruzd \& Wellman, 2014; Otterbachers, Shapiro, \& Hemphill, 2013; Wang, 2013; Xu, Sang, Blasiola, \& Park, 2014). Using Twitter for communication in education has not gone unnoticed. Educational leaders use Twitter to share and acquire resources, collaborate with other educators, build professional

Address correspondence to Yinying Wang, Department of Educational Policy Studies, College of Education, Georgia State University, P.O. Box 3977, Atlanta, GA 30302-3977. E-mail: ywang103@gsu.edu 
and personal learning networks, participate in real-time chats, and communicate with stakeholders (Carpenter \& Krutka, 2014; Cox \& McLeod, 2014).

Yet the few available studies on educational leaders' Twitter use have left a myriad of questions unanswered. For example, in their study of Twitter used by educators, including administrators, Carpenter and Krutka (2014) reported that $96 \%$ of the 755 survey respondents used Twitter to share and/or acquire ideas and resources. Their study pressed us to wonder how such information was diffused via educational leaders' communication on Twitter, and the mechanisms associated with how certain leaders became influential in diffusing information. We were particularly interested in answering the following three research questions:

- Does gender inequality exist in the educational leader's influence on information diffusion on Twitter?

- Does an educational leader's influence on information diffusion on Twitter bear a resemblance to the leadership position-based authority and power?

- What Twitter-use patterns account for a leader's influence on information diffusion on Twitter?

\section{THEORETICAL FOUNDATION AND HYPOTHESES DEVELOPMENT}

Educational leaders have been using Twitter to disseminate information for a wide variety of purposes, including resource sharing/acquiring, collaboration with other educators, and participation in ongoing discussions (Carpenter \& Kurtka, 2014). However, a piece of information does not travel in a vacuum in order to be received by an individual. Rather, the information travels via a communication channel within a social system (Rogers, 2003). In the following pages, we first review the literature on information diffusion and present in detail how the social system was conceptualized to uncover information diffusion via educational leaders' communication on Twitter. We then draw upon social network analysis literature to introduce the measurements of the individual leader's influence on information diffusion in the communication network on Twitter. Lastly, we develop the hypotheses pertaining to the aforementioned three research questions, according to the extant literature in educational leadership and the scholarship in Twitter.

\section{INFORMATION DIFFUSED IN A SOCIAL SYSTEM}

Information, communication channels, and social systems are the essential elements in diffusing information (Rogers, 2003). Below we explain how 
these three elements play out in the information diffusion via educational leaders' communication on Twitter. First, the information is contextualized in this study as any information shared in the tweets posted by educational leaders. In his diffusion of innovation theory, Rogers (2003) defined an innovation as "an idea, practice, or object that is perceived as new by an individual or other unit of adoption" (p. 12). Further, it is the perceived newness of the idea or information that matters because the individuals accept or reject the idea or information based on its perceived newness rather than the objective newness. Thus the information diffused via the educational leaders' communication on Twitter could be practices on educational leadership, updates of district/school events, and discussions on a given education-themed topic, to name a few.

In addition, the communication channel in Rogers' (2003) model of the diffusion of innovation theory is contextualized as Twitter in the current study. Twitter's functionalities, to a large extent, allow for speedy information dissemination in various ways (Torrente, Marti, \& Escarrabill, 2012). First, the 140-character limit on tweets encourages Twitter users to post instantaneous updates. Second, Twitter users can use an @ sign to direct a tweet to a particular Twitter user. Third, a hashtag (\#) helps Twitter users categorize and organize the topics of tweets. Fourth, to bypass the 140-character limit, Twitter users use web links in tweets to refer to the web pages that provide rich information. These unique functionalities rendered Twitter as the "platform most amenable to ongoing, public dialogue" (Junco, Heiberger, \& Loken, 2011, p. 1), because of brevity, immediacy, and openness in the communication on Twitter (Carpenter \& Krutka, 2014).

Social system-the third component in Roger's (2003) model-is conceptualized as a communication network consisting of vertices (in this case, the leaders who use Twitter for communication and the Twitter users being communicated) and directional ties (in this case, the communication ties regarding who talks with whom as indicated by the @ sign in tweets). As a result, the presence or absence of the vertices' communication ties could facilitate or impede the information diffusion in the communication network. In the current study, the educational leaders' communication network on Twitter does not necessarily follow a formal organizational hierarchy in which individuals in higher-ranked positions usually have more control over information flow within the organization. Therefore, to quantify an individual's influence on information diffusion in the network, we employed four well-established centrality measures-indegree, outdegree, betweenness, and closeness-in social network analysis literature (Freeman, 1977, 1979; Sabidussi, 1966; Slaugher, Yu, \& Koehly, 2009; Wasserman \& Faust, 1994) to identify the individuals who diffuse information efficiently and effectively in the educational leaders' communication network on Twitter. 
Social network analysis has been increasingly used in education research (Coburn \& Russell, 2008; Cole \& Weinbaum, 2010; Daly, 2012; Daly \& Finnigan, 2012; Finnigan \& Daly, 2012; Moolenaar, Daly \& Sleegers, 2011; Zhang, Wu, \& Ma, 2014). Shifting from a focus on individual attributes, social network analysis considers that the individuals (i.e., vertices) are interdependent rather than dependent (Degenne \& Forse, 1999; Wasserman \& Faust, 1994), and thereby focuses on the relational ties connecting the individuals and how the individuals' relational positions in the network facilitate or impede the resource exchange (Borgatti \& Cross, 2003; Burt, 2005). Moreover, what resources are exchanged is subject to the nature of relational ties in the network. For example, the knowledge and expertise are exchanged in the school leaders' adviceseeking network in which relational ties referred to who sought advice from whom (Daly, Liou, Tran, Cornelissen, \& Park, 2014). Another example is the charter school initiative in the state of Washington (Au \& Ferrare, 2014). Cash and in-kind contributions are exchanged in the charter school policymaking network in which the relational ties referred to the donated cash and in-kind contributions to the Yes on 1240 WA Coalition for Public Charter Schools' campaign. In the current study, it was the educational leaders' shared information (e.g., practices on educational leadership, updates of district/school events, discussions on a given education-themed topic, etc.) that was exchanged in the leaders' communication network on Twitter. According to the social network theory, those who occupy central structural positions exert higher influence on resource exchange in the network (Borgatti, 2005, 2006; Burt, 1999; Lin, 2009). Applying this argument to the current study, we consider that the educational leaders who are at the center of their communication network have more influence on information diffusion in the network than those in the periphery.

There is a critical point here we need to stress in order to avoid a possible over-generalization of our argument. That is, by a leader's influence, we only mean the influence on information diffusion in the leader's communication network on Twitter. While communication is essential in leadership which centers on "a relationship between leaders and followers within a social group" (Haslam, Reicher, \& Platow, 2011, p. 43), we do not intend to extend the influence scope to a broad construct in which the influence is derived from all leadership practices. Since our study focuses on educational leaders' communication on Twitter, we argue that the influence in our study should be aptly understood as the influence on information diffusion. In doing so, we stay true to the construct of influence in the social network theory which enables us to quantify individual leader's influence on information diffusion in the communication network. 


\section{MEASUREMENTS OF INDIVIDUAL INFLUENCE ON INFORMATION DIFFUSION}

Centrality is the quantitative measure of a vertex's (individual) influence by quantifying the vertex's structural position in the network (Borgatti \& Everett, 1992; Burt, 1976, 1999; Kilduff \& Krackhardt, 2008). We use four widely used centrality measures -indegree, outdegree, betweenness, and closeness-as the indicators of an educational leader's influence on information diffusion in the communication network on Twitter. These four centrality measures are all indicators of vertices' (leaders) influence in the network, but each centrality measure distinguishes itself in a unique way (Kilduff \& Krackhardt, 2008; Wasserman \& Faust, 1994), as we shall see below. Using the centrality measures of eight vertices in the example network (see Figure 1), the following subsections explain the meaning and calculation of four centrality measures.

\section{Indegree}

Indegree refers to the number of incoming ties in a network, indicating a vertex's prestige and popularity (Freeman, 1979; Wasserman \& Faust,

\begin{tabular}{|c|ccccc|}
\hline & Vertex & Indegree & Outdegree & Betweenness & Closeness \\
\cline { 2 - 6 } & $\mathrm{A}$ & 5.0000 & 4.0000 & 0.4762 & 0.7778 \\
$\mathrm{~B}$ & 1.0000 & 2.0000 & 0.0000 & 0.5000 \\
$\mathrm{C}$ & 2.0000 & 1.0000 & 0.0000 & 0.5000 \\
$\mathrm{C}$ & $\mathrm{D}$ & 1.0000 & 3.0000 & 0.0952 & 0.6364 \\
$\mathrm{E}$ & $\mathrm{E}$ & 2.0000 & 2.0000 & 0.1190 & 0.6364 \\
& $\mathrm{~F}$ & 2.0000 & 0.0000 & 0.0000 & 0.4667 \\
& $\mathrm{G}$ & 1.0000 & 1.0000 & 0.0238 & 0.4667 \\
& $\mathrm{H}$ & 0.0000 & 1.0000 & 0.0000 & 0.4667 \\
\hline
\end{tabular}

Figure 1. An example network. On the left, the network is visualized as a sociogram in which eight vertices (A, B, C, D, E, F, G, and $H$ ) are connected through 14 directional ties. The arrow of the tie shows the direction of information diffusion. On the right, we present the results of four centrality measures of each vertex after performing social network analysis. The formula to calculate a vertex's betweenness centrality in a network (i.e., graph $G$ ) with directional ties is: $C_{b}(v, G) \equiv \sum_{\left(v^{\prime}, v^{\prime \prime}\right) \in v / v} \frac{g^{\prime}\left(v^{\prime}, v, v^{\prime \prime}, G\right)}{g\left(v^{\prime}, v^{\prime \prime}, G\right)}$, where $g\left(v, v^{\prime}, G\right)$ is the number of $\left(v, v^{\prime}\right)$ geodesics-the shortest path-in $G, g\left(v, v^{\prime}, v^{\prime \prime}, G\right)$ is the number of $\left(v, v^{\prime \prime}\right)$ geodesics in $G$ containing $v^{\prime}$, and $\frac{g^{\prime}\left(v^{\prime}, v, v^{\prime \prime}, G\right)}{g\left(v^{\prime}, v^{\prime \prime}, G\right)}$ is taken equal to 0 where $g\left(v, v^{\prime \prime}, G\right)=0$ (Freeman, 1979). The formula to calculate closeness centrality is: $C_{C}(v, G) \equiv \frac{1}{\sum_{v^{\prime} \in V} d\left(v, v^{\prime}\right)}$, where $d(v, v)$ is the geodesics distance between vertex $v$ and $v^{\prime}$ (Sabidussi, 1966). 
1994). In the example network illustrated in Figure 1, five vertices (B, C, $\mathrm{D}, \mathrm{E}$, and $\mathrm{H}$ ) communicate with $\mathrm{A}$, therefore vertex A receives five incoming ties visualized as the five ties with arrows pointing at A. In Figure 1, vertex $\mathrm{A}$ has the highest indegree $\left(C_{\text {indegree }}=5.0000\right)$, meaning $\mathrm{A}$ gains its influence by serving as the information hub in the network. The removal of vertex A from the network would cut off the conduits for information diffusion to vertex $\mathrm{E}$. In the present study, an educational leader's indegree is operationalized as how many times the leader was communicated with by other Twitter users. The more frequently a leader is communicated with by others on Twitter, the more information the leader receives and thus the higher indegree the leader has.

\section{Outdegree}

Outdegree refers to the number of outgoing ties in a network (Freeman, 1979). The vertices with higher outdegree have higher influence over information diffusion because they have more conduits that can be used to send out information. In Figure 1, vertex A has the highest outdegree $\left(C_{\text {outdegree }}=4.0000\right)$ followed by vertex D $\left(C_{\text {outdegree }}=3.0000\right)$. Vertex A not only receives information from five vertices $(\mathrm{B}, \mathrm{C}, \mathrm{D}, \mathrm{E}$, and $\mathrm{H})$ as evidenced by high indegree, but also sends out information to four vertices (B, C, D, and $\mathrm{E}$ ). By contrast, vertex $\mathrm{F}$ has the lowest outdegree $\left(C_{\text {outdegree }}=0\right)$ because $\mathrm{F}$ does not send out information to any other vertex in the network, but only receives the information from vertex D and G. In our study, outdegree is operationalized as how many times an educational leader communicated with other Twitter users. The more Twitter users a leader communicates within the network, the more efficiently the leader diffuses the information.

\section{Betweenness}

In comparison with indegree and outdegree, a distinct aspect of betweenness is that it takes into account a vertex's neighbors and their ties in the network. In other words, betweenness indicates to what extent a vertex stands between other vertices in the network. In Figure 1, the betweenness of vertex $B$ is zero, because the information from vertex $A$ can reach $\mathrm{C}$ directly without $\mathrm{B}$ as an intermediate person. According to Freeman (1979), when we calculate the betweenness of vertex B, we look at the shortest distance between vertex $A$ and $C(A \rightarrow C)$, rather than the alternative path $\mathrm{A} \rightarrow \mathrm{B} \rightarrow \mathrm{C}$. The removal of vertex $\mathrm{B}$ from the network in Figure 1 does not prevent vertex $\mathrm{C}$ from receiving information from $\mathrm{A}$; therefore, the betweenness of vertex B is zero, denoting B's minuscule influence, 
as measured by betweenness, on information diffusion in the network. By contrast, vertex A has the highest betweenness, meaning vertex A stands between its neighbors in the network, such as the information diffusion paths $\mathrm{H} \rightarrow \mathrm{A} \rightarrow \mathrm{D}$ and $\mathrm{C} \rightarrow \mathrm{A} \rightarrow \mathrm{E}$. Vertex A's influence in the network comes from A's structural position among A's neighbors, functioning as the information brokers or boundary spanners in the network. In our study, high-betweenness educational leaders tend to act as information brokers, bridging other Twitter users who are otherwise rarely communicated, if at all.

\section{Closeness}

Closeness represents proximity prestige by quantifying how close-the inverse distance-a vertex is to others in the network ( $\mathrm{Lin}, 1976)$. The higher closeness of a given vertex, the shorter distance a piece of information needs to travel in the network. Again, in Figure 1 vertex A has the highest closeness $\left(C_{\text {closeness }}=0.7778\right)$ followed by vertex $\mathrm{D}$ and $\mathrm{E}$ $\left(C_{\text {closeness }}=0.6364\right)$ due to vertex A's central location in the network and thereby has the shortest distance to the rest of the vertices in the network.

In sum, the four centrality measures introduced above are conceptually distinct and are calculated in a noticeably different manner, although they all indicate vertices' influence on information diffusion in the network. The leaders emerge as influentials in the network by occupying central positions through different mechanisms. Some leaders gain influence on information diffusion by being communicated with by a large number of Twitter users in tweets-as evidenced by high indegree-and thus receive a large amount of information. Some frequently communicate other Twitter users in tweets - as evidenced by high outdegree-to send information to others. Those high-betweenness leaders gain control over information flow by strategically placing themselves between other Twitter users who otherwise rarely communicate with each other in tweets. Others communicate with a large number of Twitter users, instead of communicating with a few Twitter users repeatedly, so that they are, social network structurally speaking, close to other Twitter users and thus have high closeness.

\section{THE INDIVIDUAL LEADER'S INFLUENCE ON INFORMATION DIFFUSION ON TWITTER}

After conceptualizing a communication network in which information is diffused from one leader to another on Twitter, as well as proposing quantitative measures of individual leader's influence on information diffusion in the network, we questioned what are the potential factors associated 
with the educational leader's influence in the communication network on Twitter. Given the fact that this study intersects educational leadership and online communication, in particular social media-based communication, we reviewed the literature in both domains and formulated our hypotheses accordingly.

\section{Gender}

Women, according to Duggan (2013), are more avid users in comparison with men on social networking websites. Among Internet users, the proportion of women who used social media sites was 10 percentage points higher than men on average from 2009 to 2012 . When limited to the social networking site of Twitter, however, Duggan found no substantial difference between male (18\%) and female (17\%) participation. The current study is interested in not only how many male and female educational leaders use Twitter actively, but also their influence on information diffusion in the leaders' communication network on Twitter. Therefore, we went a step further to examine whether male and female leaders wield the same level of influence in online communities. Looking at blogs, Pedersen and Macafee (2007) argued that a new form of gender inequality might emerge in the blogosphere. Because, while female bloggers posted more blog entries, men's blog entries received more comments (Ratliff, 2006) and garnered more mainstream media attention (Herring, Kouper, Scheidt, \& Wright, 2004). It appeared that online community intensified gender disparity, rather than "neutralizing gender" (Pedersen \& Macafee, 2007, p. 1473), despite the fact that male and female Internet users were provided with equal access to participating in these online communities. Applying these findings to Twitter, we hypothesized that gender inequality exists in the leaders' communication network on Twitter. This leads to our first hypothesis:

Hypothesis 1: Male educational leaders have higher influence than female leaders on information diffusion, as measured by centrality, in their communication network on Twitter.

\section{Leadership Position}

How does a district- and building-level leader's influence on information diffusion differ in the communication network on Twitter? A leader's position in an organizational hierarchy grants the leader hierarchy-based legitimate power and thus offline social influence (Cialdini \& Goldstein, 2004; Raven, Schwarzwald, \& Koslowsky, 1998). However, online communities 
are "the informal networks of collaboration that naturally grow and coalesce within and outside organizations" (Huberman \& Adamic, 2004, p. 372). Twitter, by its very nature, is a communication channel that allows any Internet user to participate in conversations regardless of an individual's offline position in an organizational hierarchy. Thus in the context of a communication network on Twitter, we argue that a leader's influence on information diffusion in the network does not derive from his or her offline leadership position-based authority and power. Rather, in an arguably leveled social system of information diffusion such as a communication network on Twitter, influentials emerge as they occupy central positions in the network by strategically building communication ties with others in the network. Therefore, it can be expected that a district- or building-level leader's offline leadership position is not a determinant of the leader's influence on information diffusion in the communication network on Twitter.

Hypothesis 2: Holding different leadership position (district vs. building) has no significant relationship with the educational leader's influence on information diffusion, as measured by centrality, in the communication network on Twitter.

\section{Twitter-Use Patterns}

What Twitter-use patterns are associated with the leader's influence on information diffusion in the communication network on Twitter? In the current study, since Twitter is the communication channel used by leaders, we argue that how Twitter is used by the leader for communication is likely to impact the leader's influence on information diffusion in the communication network. The Twitter-use patterns that have been widely examined in the existing literature are: (1) presence or visibility on Twitter, as indicated by the size of Twitter followers and Twitter following; (2) frequency of tweets, as indicated by the number of tweets per week; and (3) how long has Twitter been used by a given user, as indicated by the Twitter account creation (Bae \& Lee, 2012; Marques, Aquino, \& Miola, 2014; Stieglitz \& Dang-Xuan, 2013; Thackeray, Neiger, Smith, \& Wagenen, 2012).

The follower/following relationship between Twitter user A and B, according to Twitter glossary (Twitter.com, 2014b), is formed when Twitter user A subscribes to B's tweets. On Twitter, if A is following B, then A becomes B's follower. But the Twitter follower/following relationship is not necessarily reciprocal. Twitter user B might choose not to follow A, but follow user C and D on Twitter instead. Regardless, the large size of 
Twitter follower and following suggests a Twitter user has high visibility on Twitter and thereby accelerates information diffusion. Therefore, we derive the following hypotheses:

Hypothesis 3a: The more Twitter followers a leader has, the more influence the leader has on information diffusion, as indicated by higher centrality, in the leaders' communication network on Twitter.

Hypothesis $3 b$ : The more Twitter following a leader has, the more influence the leader has on information diffusion, as indicated by higher centrality, in the leaders' communication network on Twitter.

In addition, frequency of tweets (i.e., tweets per week) denotes a given Twitter user's efficiency in using Twitter to post information (Marques et al., 2014). We therefore argue that a leader's frequent tweet postings would allow the leader to contribute frequently to the information diffused on Twitter, which grants the leader more influence on information diffusion in the communication network than those who tweet less frequently. As a result, the following hypothesis is posited:

Hypothesis 3c: The more tweets a leader posts per week, the more influence the leader has on information diffusion, as indicated by higher centrality, in the leaders' communication network on Twitter.

Lastly, we also assume that if a leader created a Twitter account early on, the leader would have more time to build communication relationships with Twitter users, and thereby gain more influence on information diffusion in the communication network than those whose Twitter accounts are newer. This leads us to formulate the following hypothesis:

Hypothesis 3d: The leader whose Twitter account is older has more influence on information diffusion, as indicated by higher centrality, in the communication network on Twitter.

According to the extant literature on how Twitter was used by educators (Carpenter \& Krutka, 2014), Twitter appears to be a communication platform for educational leaders to share insights and resources, as well as collaborate and discuss specific topics of interests. Yet educational leadership scholarship has devoted limited attention to a leader's use of Twitter to disseminate information via publically visible communication on Twitter. Our current analysis thus examines possible factors that might be associated with the leader's influence on information diffusion in the communication network on Twitter based on the data collected for this study. 


\section{METHODS}

The purpose of the current study is to investigate the relationship between a leader's gender, leadership position, Twitter-use patterns, and the leader's influence on information diffusion in the communication network on Twitter. We implemented our study through a five-phase procedure, as summarized in Table 1. The first four phases revolve around the data collection and processing for the multiple regression analyses conducted in Phase 5. The details of how we carried out this study are presented in this section.

\section{PHASE 1: IDENTIFY ACTIVE TWITTER USERS HOLDING EDUCATIONAL LEADERSHIP POSITIONS}

The population for our study is all district- and building-level leaders who are active Twitter users. The assumption of focusing on active Twitter users is that those who do not use Twitter actively do not exert much influence on the information diffusion on Twitter. Thus, we started with identifying the active Twitter users who held educational leadership positions in order to construct the leaders' communication network on Twitter.

Based on prior research on identifying active Twitter users (Sauers \& Richardson, 2015; Veletsianos, 2011), we used four inclusion criteria to identify educational leaders who have been using Twitter actively. The criteria are that a participant must have: (1) a public Twitter profile,

Table 1. Summary of the Methods in the Present Study

\begin{tabular}{|c|c|}
\hline & Procedures and Results \\
\hline Phase 1 & $\begin{array}{l}\text { Using four inclusion criteria, } 151 \text { district- and building-level leaders were } \\
\text { identified as the active Twitter users. }\end{array}$ \\
\hline Phase 2 & $\begin{array}{l}\text { Using the extracted network data from } 30,200 \text { tweets generated by } \\
151 \text { leaders in the sample, the educational leaders' communication } \\
\text { network on Twitter was constructed. }\end{array}$ \\
\hline Phase 3 & $\begin{array}{l}\text { The data on six independent variables (gender, position, follower, follow- } \\
\text { ing, tweets per week, and the time joined Twitter) were retrieved from the } \\
\text { leaders' public Twitter profiles and Twitter feed. }\end{array}$ \\
\hline Phase 4 & $\begin{array}{l}\text { Social network analysis was performed to calculate four centrality } \\
\text { measures (indegree, outdegree, betweenness, and closeness) which } \\
\text { are the indicators of the leader's influence on information diffusion in } \\
\text { the network. Each of four centrality measures becomes the dependent } \\
\text { variable in the regression models. }\end{array}$ \\
\hline Phase 5 & $\begin{array}{l}\text { Performed multiple regression analyses to examine the relationship } \\
\text { between the leader's gender, leadership position, Twitter-use patterns, } \\
\text { and the leader's influence on information diffusion in the network. }\end{array}$ \\
\hline
\end{tabular}


(2) more than 2,000 Twitter followers, (3) a K-12 district- or building-level leadership title listed in public Twitter profile, and (4) an active presence on Twitter.

Applying these criteria, we analyzed 20 public Twitter lists related to the field of educational leadership (UCEA Center for the Advanced Study of Technology Leadership in Education, 2014). Twitter list is a function on Twitter.com, which allows an individual to build a curated group of Twitter users around a given topic (Twitter.com, 2014c). The Twitter lists used in this study had names such as "school administrators" and "k12-schooladministrators," as well as other names related directly to K-12 school leadership such as "connected-principals" and "edtech/principals PLN." These Twitter lists were identified by searching through the lists created by the individuals who were not only in the field of educational leadership but also maintained an active presence on social media. Considering Twitter's core functionality in promoting an open, publicly visible communication (Junco et al., 2011), it would be rather difficult for active users to be invisible on Twitter and thus not be included in one or more of the Twitter lists noted above.

Each Twitter account on those 20 Twitter lists was examined to determine if the Twitter user met criterion 2 of over 2,000 Twitter followers. This procedure allowed us to identify 380 educational leaders with over 2,000 followers. Next, those who did not have an explicit K-12 district- or building-level leadership title (e.g., superintendent, assistant superintendent, principal, and assistant principal) on their public Twitter profiles (criteria 3) were excluded from our study. The individuals with general titles such as lead learner or director of curriculum on their Twitter profiles were also excluded. Thus, $153 \mathrm{~K}-12$ educational leaders were left to be examined if they met criterion 4 .

The last step in identifying active Twitter users for the current study was to ensure the participants had an active presence on Twitter-at least one tweet per week as defined by Java, Song, Finin, and Tseng (2007). We used TwimeMachine, a tweet archiving tool, to collect the 153 leaders' tweets and the corresponding date stamps, indicating when the tweets were generated. With these data, we calculated the average number of tweets per week for each of 153 educational leaders. A total of 151 individuals met criterion 4 .

As a result, we identified 151 district- and building-level leaders who met all four criteria (see Table 2). Among 151 active Twitter users holding educational leadership positions, 123 were male and 28 female. Moreover, 47 were district-level leaders and 104 building-level leaders. Further, 134 leaders self-reported their geographic locations in public Twitter profile: 107 are from the United States, 22 from Canada, four from Australia, and one from England. 
Table 2. Gender and Leadership Position of 151 District and School Building Leaders

\begin{tabular}{lcrr}
\hline & \multicolumn{2}{c}{ Leadership Position } & \\
\cline { 2 - 3 } Gender & District level & Building level & Total \\
\hline Male & $43(28.48 \%)$ & $80(52.98 \%)$ & $123(81.46 \%)$ \\
Female & $4(2.65 \%)$ & $24(15.89 \%)$ & $28(18.54 \%)$ \\
Total & $47(31.13 \%)$ & $104(68.87 \%)$ & $151(100.00 \%)$ \\
\hline
\end{tabular}

\section{PHASE 2: NETWORK CONSTRUCTION}

To investigate each of 151 active educational leader's influence on information diffusion, we constructed the network by looking at how they communicated via tweets. The @ sign in a tweet suggests a Twitter user talks to other user(s). For instance, the principal of New Milford High School in New Jersey (Twitter ID: @nmhs_principal) tweeted “@khurdhorst @tritonkory @brynmw We are fortunate to have about 1:3 right now, but BYOD then gets us close to 1:1" on March 28, 2014. This tweet indicates the principal (@nmhs_principal) communicated with three Twitter users (@khurdhorst, @tritonkory, and @brynmw). Therefore, the network data extracted from this tweet include four vertices (nmhs_principal, khurdhorst, tritonkory, and brynmw) and three directional ties (nmhs_principal $\rightarrow$ khurdhorst, nmhs_principal $\rightarrow$ tritonkory, and nmhs_principal $\rightarrow$ brynmw). The arrow of the directional tie reflects who communicates with whom. It is important to note that in our study of communication network, the communication tie refers to who talked to whom, instead of who followed whom on Twitter, because the @ sign in tweets accurately demonstrates who communicates with whom.

As an exploration, we extracted the network data from the 30,200 tweets that were the latest 200 tweets of each of 151 active district- and building-level leaders as of April 4, 2014. Even these latest 200 tweets of each individual revealed a quite large communication network that contained 34,582 vertices (Twitter users) and 53,375 ties (being communicated by or communicate with other Twitter users in tweets). Pajek 3.15 (Batagelj \& Mrvar, 2011), a large-scale social network analysis program, was used to calculate each Twitter user's indegree, outdegree, betweenness, and closeness centrality.

\section{PHASE 3: INDEPENDENT VARIABLES}

Four multiple regression models were developed to test the four hypotheses presented earlier. In each model, the six independent variables (the leader's gender, leadership position, and Twitter-use patterns) remained 
the same. Each of four centrality measures-as the indicators of the leader's influence on information diffusion in the network-is the dependent variable in regression models. Table 3 presents the descriptions of all variables used in the regression analyses. This subsection explains how the independent variables were collected, followed by the calculations of the dependent variable in the next subsection.

The data on the six independent variables regarding the leader's gender, leadership position, and Twitter-use patterns were all collected from the leader's public Twitter profile. Here, six independent variables were constructed for the present study:

1. binary variable for the gender of educational leaders: gender;

2. binary variable for the leadership position at the district- or building level: position;

3. number of Twitter followers of educational leaders: follower;

4. number of Twitter following of educational leaders: following;

5 . average number of tweets per week (TPW); and

6. time elapsed since Twitter account creation date: time (in days).

Table 3. Description of Variables in Regression Analyses

\begin{tabular}{|c|c|}
\hline Variable & Description \\
\hline \multicolumn{2}{|c|}{ Independent variables } \\
\hline Gender & Male leaders coded as 0 , female leader coded as 1 . \\
\hline Position & $\begin{array}{l}\text { Superintendents and assistant/associate superintendents are con- } \\
\text { sidered as district-level leaders, who are coded as } 0 \text {. Principals } \\
\text { and assistant/associate principals were considered as building- } \\
\text { level leaders, who are coded as } 1 \text {. }\end{array}$ \\
\hline Followers & The number of Twitter followers, as of April 4, 2014. \\
\hline Following & The number of Twitter following, as of April 4, 2014. \\
\hline TPW & The average number of tweets each week, as of April 4, 2014 . \\
\hline Time & $\begin{array}{l}\text { The number of days since the Twitter account had been created, } \\
\text { as of April } 4,2014 \text {. }\end{array}$ \\
\hline \multicolumn{2}{|c|}{ Dependent variables } \\
\hline Indegree & $\begin{array}{l}\text { The number of vertices that communicated a given vertex in the } \\
\text { tweets. }\end{array}$ \\
\hline Outdegree & $\begin{array}{l}\text { The number of vertices that a given vertex communicated with in } \\
\text { the network. }\end{array}$ \\
\hline Betweenness & $\begin{array}{l}\text { A numeric measure of a given Twitter user's influence on informa- } \\
\text { tion diffusion by using Freeman's (1979) betweenness calcula- } \\
\text { tion formula. }\end{array}$ \\
\hline Closeness & $\begin{array}{l}\text { A numeric measure of a given Twitter user's influence on informa- } \\
\text { tion diffusion by quantifying how close the Twitter user is to } \\
\text { other Twitter users in the network. Closeness centrality was } \\
\text { calculated by Sabidussi's (1966) formula. }\end{array}$ \\
\hline
\end{tabular}


Table 4 shows the basic Twitter account statistics for 151 district- and building-level leaders at the time of data collection.

\section{PHASE 4: DEPENDENT VARIABLES}

Each of the 151 leader's centrality measures-indegree, outdegree, betweenness, and closeness-was calculated by performing a social network analysis. Then, each of four centrality measures, as the indicator of individual leader's influence on information diffusion in the communication network on Twitter, became the dependent variable in regression models.

\section{PHASE 5: REGRESSION ANALYSES}

Prior to regression analyses, four variables were logarithmically transformed to reduce skewness. These include Twitter follower, Twitter following, tweets per week, and indegree. The previous research suggests Twitter follower and tweets per week follow the log-normal distribution (Marques et al., 2014). We also found the logarithm of Twitter following and indegree reduce the distribution skewness for the regression analyses.

\section{FINDINGS}

The educational leaders in this study's dataset used Twitter with varying levels of intensity. A high degree of skewness is observed in the size of both Twitter followers and following, as seen in Table 4 . The number of Twitter followers ranged widely from 2,023 to 59,348 . The median Twitter following number was 1,707 that was approximately one-tenth of the largest Twitter following number at 17,716. Some leaders tweeted twice per week, whereas others tweeted as many as 220 times per week. The oldest Twitter account was created on January 20, 2007 not very long after

Table 4. Descriptive Statistics of 151 District- and Building-Level Leaders' Twitter Accounts

\begin{tabular}{lrrrr}
\hline & Min. & Max. & Median & Mean \\
\hline Followers & 2,023 & 59,348 & 3,238 & 5,484 \\
Following & 28 & 17,716 & 1,707 & 2,305 \\
TPW & 2 & 220 & 38 & 49 \\
Time & 540 & 2,744 & 1,692 & 1,593 \\
\hline
\end{tabular}


Twitter's launch in 2006, whereas the newest Twitter account was created on October 22, 2012. If the leaders' Twitter-use patterns demonstrate such considerable variations, then which Twitter-use patterns are associated with individual leader's influence on information diffusion in the communication network on Twitter? Returning to the three research questions laid out at the beginning of this article, we examined the educational leader's influence on information diffusion in the communication network on Twitter.

Multiple regression analyses were performed to uncover the relationships between the leader's gender, leadership position, Twitter-use patterns, and the leader's influence on information diffusion in the communication network on Twitter. In each multiple regression model, the six independent variables (the leader's gender, leadership position, and Twitter-use patterns) remained the same. Each of four centrality measures-as the indicator of the leader's influence on information diffusion in the network-is the dependent variable in each regression model. The correlation matrix of six independent variables is presented in Table 5. Variance inflation factors for each model range from 1.038 to 1.886 , indicating multicollinearity is not a problem in our data. According to the results of multiple regression analyses (see Table 6), model 4 was significant in explaining $19.8 \%$ of the variance in the leader's influence on information diffusion in the network as measured by closeness, $F(6,144)=5.915, p<.01$. This means gender, Twitter followers, and following significantly predict the leader's closeness in the communication network on Twitter. Similarly, model 1 was also significant in explaining $15 \%$ of the variance in indegree, $F(6,144)=4.243, p<.05$. However, gender, leadership position, or Twitter-use patterns did not predict the educational leader's outdegree and betweenness in the network. Here we present in details the findings of the three research questions in our study.

Table 5. Correlation Matrix of Independent Variables $(n=151)$

\begin{tabular}{lccllll}
\hline & Gender & Position & Follower & Following & TPW & Time \\
\hline Gender & 1.000 & & & & & \\
Position & $0.174^{*}$ & 1.000 & & & & \\
Follower & $-0.140^{*}$ & -0.089 & 1.000 & & & \\
Following & -0.031 & $0.264^{*}$ & $0.189^{*}$ & 1.000 & & \\
TPW & 0.036 & $0.259^{*}$ & $0.455^{*}$ & $0.360^{*}$ & 1.000 & \\
Time & -0.008 & 0.109 & $0.261^{*}$ & $0.258^{*}$ & -0.019 & 1.000 \\
\hline
\end{tabular}

*significant at 0.05 level.

Male is coded as 0 , female is coded as 1 ; district-level leaders are coded as 0 ; building-level leaders are coded as 1. 


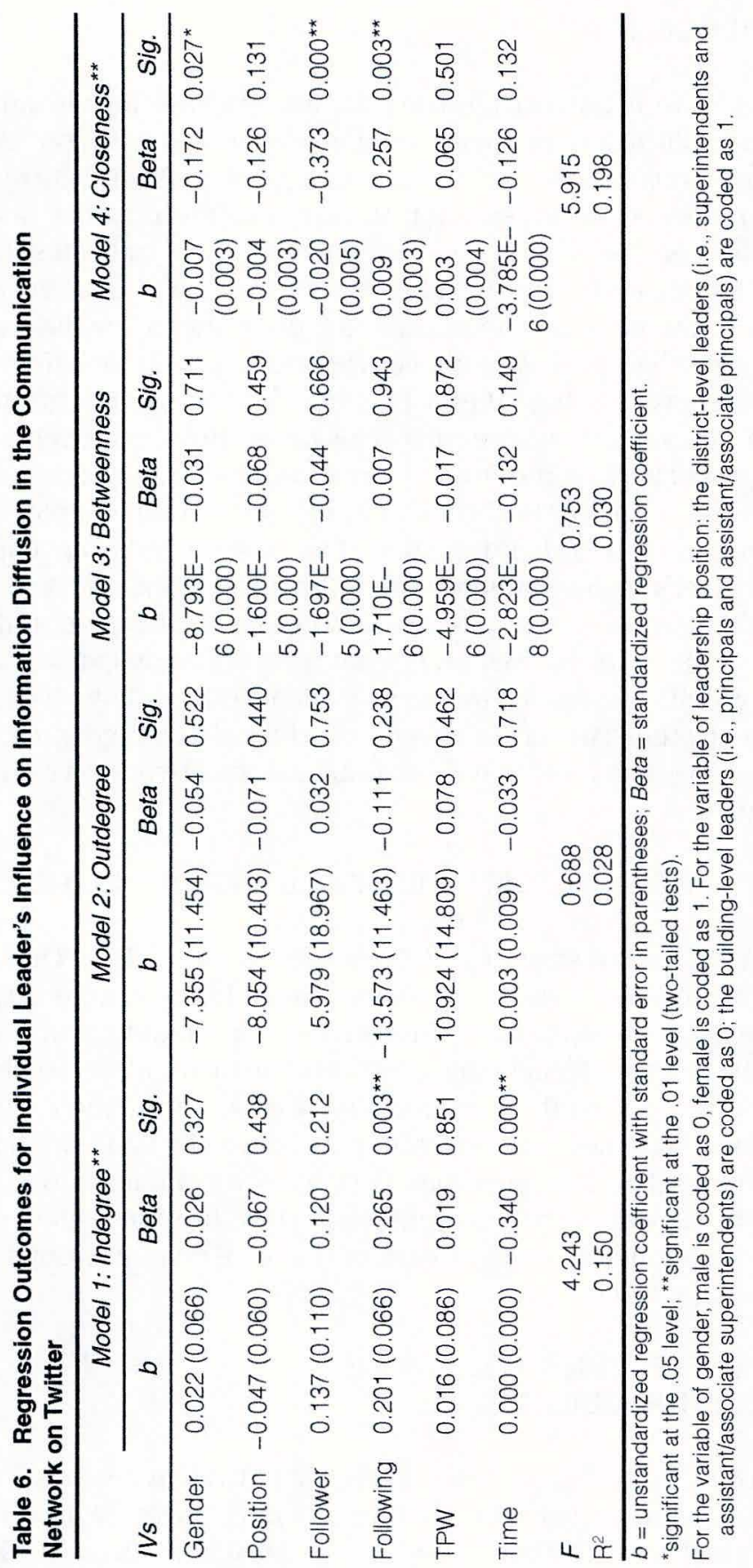


GENDER: INEQUALITY

In hypothesis 1 , we hypothesized that male leaders have higher influence on information diffusion in their communication network on Twitter. According to the regression results of model 4 , gender statistically predicts the leader's influence on information diffusion in the network, as measured by closeness. The standardized coefficient $(-.172)$ indicates that the closeness of female educational leaders is .172 unit lower than their male counterparts in the network. As explained earlier, the lower the value of closeness a leader has, the less influence the leader has on the information diffusion in the network. Hypothesis 1 is, therefore, supported by model 4 in which the influence is measured by closeness. However, hypothesis 1 was not supported by the other three regression models in which the leader's influence on information diffusion is measured by indegree, outdegree, and betweenness. Taken together, these results indicate that male educational leader's higher influence on information diffusion comes from positioning themselves structurally close to other Twitter users in their communication network on Twitter, but not from (1) being communicated with by other Twitter users in tweets, as evidenced by indegree; (2) communicating with other Twitters in tweets, as evidenced by outdegree, or (3) being the boundary spanners in the communication network, as evidenced by betweenness.

\section{LEADERSHIP POSITION: FLATTENED INFLUENCE STRUCTURE}

Our hypothesis 2 is supported by all four regression models. That is, no significant relationship existed between leadership positions and the leader's influence on information diffusion in the communication network on Twitter. The change of leadership position from district level to building level has little to do with the leader's influence on information diffusion in the communication network on Twitter, measured by all four centrality measures. This finding indicates that Twitter, as a communication channel, appears to provide a flattened influence structure for leaders to disseminate information online, regardless of the leadership positions at the district or building level.

\section{TWITTER-USE PATTERNS: FOLLOWING} IS THE BIGGEST PREDICTOR

The results of four hypothesis tests regarding individual leader's Twitteruse patterns are mixed, as seen in Table 7. Hypothesis $3 \mathrm{a}$ is rejected, because the number of Twitter followers is negatively associated with the 


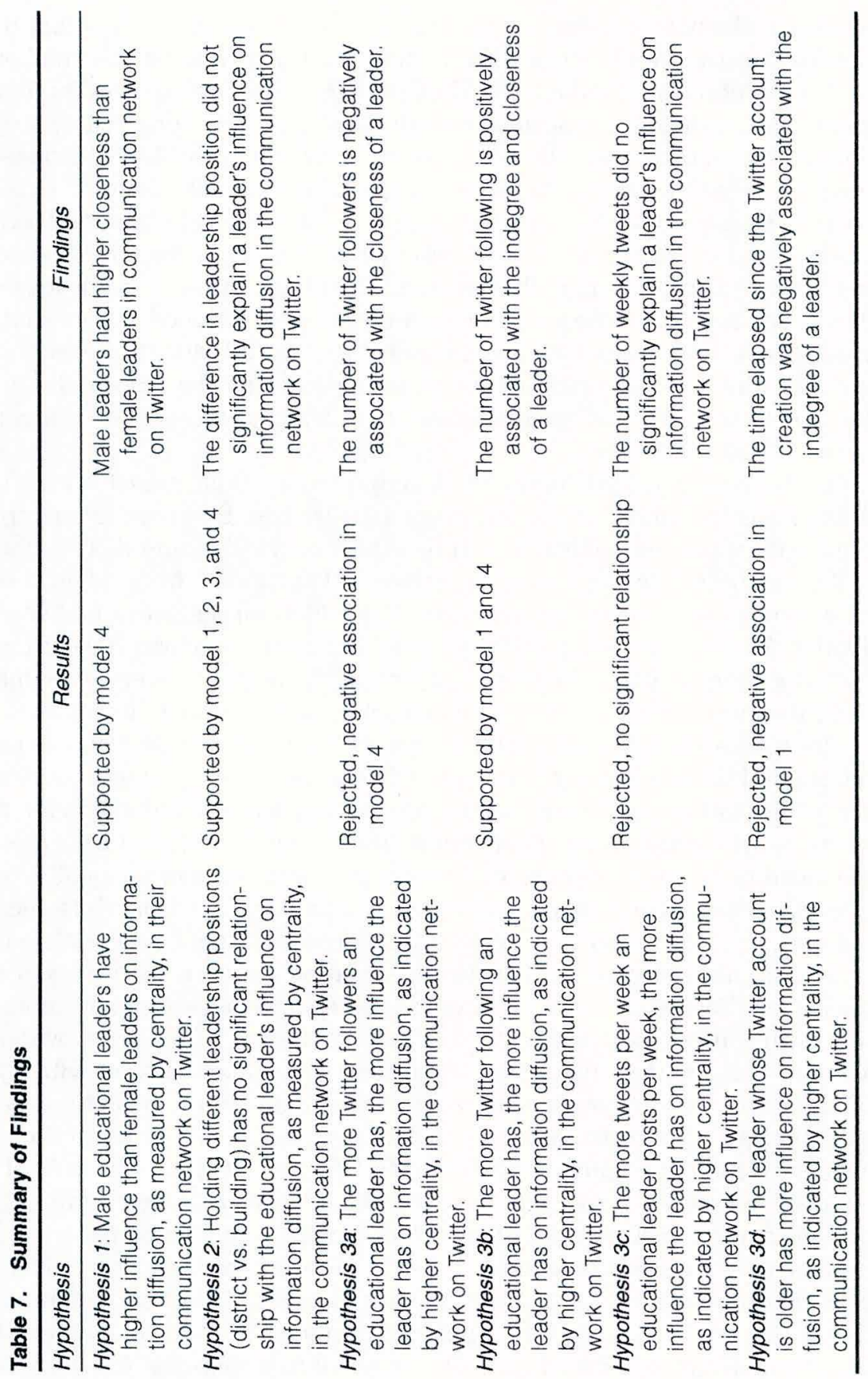


leader's influence on information diffusion in the network, according to the standardized coefficient (-.373) in model 4 . The increase in the number of Twitter followers is linked to a .373 unit of decrease in closeness. At first glance this finding might seem counterintuitive, but it is fairly reasonable after factoring in the definition of closeness centrality (see Table 3): closeness quantifies the inverse distance of a given Twitter user to other Twitter users in the network. Consequently, the more followers a Twitter user has, the longer the distance a piece of information needs to travel in order to reach other Twitter users in the network. The longer distance yields lower closeness, because closeness indicates the inverse distance. As a result, the negative association between the size of a leader's Twitter follower and the leader's closeness might derive from the fact that the information in the tweet had to travel a longer distance in order to be received by a larger base of Twitter followers.

On the contrary, hypothesis $3 \mathrm{~b}$ is supported by both model 1 and 4 . This means the more Twitter following a leader had, the more frequently the leader was communicated with by others on Twitter, and thereby the higher indegree a leader has in the network. This finding from model 1 is in agreement with the finding from model 4 , which suggests the number of Twitter following is also positively associated with closeness. Put differently, the more Twitter following a leader had, the higher the closeness, the more the influence the leader had on information diffusion in the network.

The results in Table 7 did not offer support for hypothesis $3 \mathrm{c}$. This can be interpreted that the average number of tweets per week does not predict any of the influence measure in the educational leaders' communication network on Twitter. Our explanation is that the current study focused on the quantity of weekly tweets, but did not take into account the quality of tweets, such as what web links or hashtags shared by each leader's tweets.

Lastly, hypothesis $3 \mathrm{~d}$ was rejected, because the standard coefficient $(-.340)$ in model 1 shows a negative association between the time since the leader's Twitter account creation and the leader's influence on information diffusion in the network. In other words, the older a leader's Twitter account was, the less frequently the leader was communicated with by others in the communication network. One explanation is that it is possible that a leader registered a Twitter account early on, but did not use Twitter actively until later. In other words, being an early adopter of Twitter does not necessarily grant the educational leader's larger influence on information diffusion on Twitter. This finding is encouraging for the leaders who have not registered a Twitter account or have not actively used Twitter, because proactively building dense and diverse communication ties on Twitter, and thus positioning themselves at the center of the communication network, is more effective in developing the leader's 
influence on information diffusion on Twitter, as evidenced by the results on hypothesis $3 \mathrm{~b}$.

\section{DISCUSSION}

The purpose of the current study was to investigate the relationship between the leaders' gender, leadership position, Twitter-use patterns, and the leader's influence on information diffusion in the communication network on Twitter. This study adds to the currently scarce scholarship on Twitter use in the field of educational leadership. Our study is novel and significant for four main reasons. First, we situated the study within a social network in which information diffused across the leaders' communication network on Twitter. It is within this socially constructed network that we advanced our understanding of the factors that were associated with the educational leader's influence on information diffusion in the network on Twitter. Second, we found the evidence of gender inequality existed in educational leader's influence on information diffusion in the communication on Twitter. Third, Twitter appears to blur the boundaries in offline, formal organizational communication hierarchy. Fourth, the results of our study confirmed a nonsignificant relationship between a particular Twitter user's size of Twitter follower and the influence on information diffusion in communication network on Twitter, as argued by some scholars previously (Adi, Erickson, \& Lilleker, 2014). Some of these findings are related to the existing literature, while some run counter to what we hypothesized. We will discuss the major findings and implications below.

We developed hypothesis 1 based on the literature that suggests gender inequality in the blogosphere (Herring et al., 2004; Ratliff, 2006). We thus hypothesized that male leaders had higher influence on information diffusion than female leaders in the communication network on Twitter. Hypothesis 1 was supported by model 4, and we interpreted this finding as the effect of the larger number of male leaders than female leaders in the network. The existing literature shows that K-16 female educators (i.e., teachers, administrators, teacher educators, and librarian/media specialists) who used Twitter outnumbered male educators (Carpenter \& Krutka, 2014), which was consistent with the trend in the general population of Twitter users (Duggan, 2013). However, female leaders in our sample did not appear as enthusiastic as their male counterparts about using Twitter, because we found the male leaders $(n=123)$ substantially outnumbered female leaders $(n=28)$ in the leaders' communication network. Therefore, the under-representation of female leaders in the network might explain their lower influence on information diffusion in the network. This finding 
also poses further unanswered questions for future inquiry: Why do female educational leaders not interact as much as male leaders do on Twitter? Why do more female than male educators embrace Twitter, as indicated in Carpenter \& Krutka's (2014) study, whereas female leaders lag behind in terms of Twitter use?

How does the difference in leadership position translate to the leader's influence on information diffusion in the communication on Twitter? One of the key findings of our study is that Twitter appears to be agnostic to hierarchies in education discourse by blurring the boundaries in formal organizational structure between district- and building-level leaders. Regardless of offline leadership positions, individuals emerge as influentials when they occupy central positions and thus exert high influence on information diffusion in the communication network. Those who have high centrality in the communication network are, in effect, called opinion leaders by Rogers (2003). On a communication platform as anarchic as Twitter (Adi et al., 2014), users have greater freedom to disseminate information across their communication network on Twitter than offline social networks. Therefore, the influence on information diffusion on Twitter does not necessarily derive from offline leadership position-based authority and power, but rather a result of strategically building dense and diverse communication ties on Twitter. This divergence of offline and online influence of educational leaders poses an emerging challenge for the leaders on how to harness the communication potential of Twitter to translate their offline power and influence to online power and influence.

This study also demonstrated the size of Twitter following is a significant predictor of a leader's influence in the communication network on Twitter, as evidenced in model 1 and 4. This finding adds to a growing body of literature that argues the size of Twitter follower is not an accurate metric of a Twitter user's influence (Bakshy, Hofman, Mason, \& Watts, 2011; Cha, Haddadi, Benevenuto, \& Gummadi, 2010; Cresci, Petrocchi, Spognardi, Tesconi, \& Pietro, 2014; Weng, Lim, Jiang, \& He, 2010). Specifically, the findings of this study - situated in the educational leaders' communication network on Twitter-are consistent with existing literature, such as a previous study on political leaders' communication network on Twitter where Adi and colleagues (2014) reported noncorrelated relationships between the size of Twitter followers, Twitter usage frequency as measured by tweets, and communication network centrality.

Two major practical implications arise from this study. First, educational leaders need to proactively expand their communication network on Twitter by following other Twitter users. Following others whose tweets are appealing is indeed one of the recommended practices of Twitter use (Twitter.com, 2014a). For leaders, enlarging the size of Twitter following 
is merely a starting point, because proactively following others on Twitter could bring more Twitter followers (Twitter.com, 2014a), as well as develop a dynamic online social system in which leaders can communicate with one another and thus diffuse information effectively and efficiently. Second, leaders should not place an exclusive focus on the number of weekly tweets. None of the four influence measures in this study is predicted by the number of tweets per week. We acknowledge that the current study does not take into account the web links, the number of hashtags, or which hashtags were present in the tweets. It is possible that a widely used hashtag (e.g., \#edtech) in the tweets would allow the tweets to reach a larger number of Twitter users than a rarely recognized hashtag by Twitter users. This also warrants further studies to examine the role of tweet content in diffusing information in the leaders' communication network.

\section{LIMITATIONS}

We recognize that our study was limited in the following ways. First, as an exploratory study, we only analyzed the latest 200 tweets from each of 151 leaders who used Twitter actively. More tweets included in the analyses would generate a larger communication network, which might produce a more robust network depicting the information diffusion across leaders' communication network on Twitter. Second, we operationalized active Twitter users as those whose Twitter accounts had at least 2,000 followers. In this study, we did not detect a significant relationship between the size of the leader's Twitter follower and the leader's influence on information diffusion in the communication network on Twitter. Caution needs to be exercised to interpret this finding, because the variance in the size of Twitter followers in our study might be too small to yield a significant difference in the variance of four centrality measures that indicate individual leader's influence on information diffusion. Third, in this study we only investigated the information diffused via the communication relationships in tweets. Future inquiry on the information diffused via hashtags would add valuable insights to the leaders' communication on Twitter, because the tweets with hashtags are readily searchable and thereby contribute to advancing a given conversation on a specific theme (Adi et al., 2014). Lastly, we focused on examining the potential factors associated with the leader's influence on information diffusion in the network, without taking into account who were engaged in the leaders' communication network. It is, therefore, unknown as to what extent the offline identities of whom a leader communicated with on Twitter would explain the leader's influence on information diffusion in the network. 


\section{SUGGESTIONS FOR FUTURE INQUIRY}

Previous research (e.g., Carpenter \& Krutka, 2014; Cho, Ro, \& LittenbergTobias, 2013; Cox \& McLeod, 2014) and the current study present snapshots of Twitter use in education. All are valuable contributions, but to gain a richer understanding of the role Twitter plays in the field of educational leadership, more work is needed. One direction for future studies could involve dynamic, time-series analyses of Twitter used by leaders at multiple time points. For example, future studies could aim at how a leader's influence on information diffusion in the communication network on Twitter changes over time, because the network is arguably subject to constant evolution when new communication ties are formed. In addition, our study could be further extended to examine the web links and education-themed hashtags used by leaders, and subsequently determine the role of tweet content in diffusing information across the leaders' communication network on Twitter. Moreover, a fruitful route for further research is to compare offline and online communication, in particular on the communication channel of Twitter, organizational communication network to answer the questions like: How does offline educational leadership differ from opinion leadership on Twitter? Moreover, more comprehensive work is required to analyze how the leaders' communication network on Twitter is intertwined with other education stakeholders' (e.g., teachers, parents, and communities) communication networks.

\section{REFERENCES}

Adi, A., Erickson, K., \& Lilleker, D. G. (2014). Elite tweets: Analyzing the Twitter communication patterns of Labour Party peers in the House of Lords. Policy \& Internet, 6(1), 1-27.

$\mathrm{Au}, \mathrm{W} .$, \& Ferrare, J. J. (2014). Sponsors of policy: A network analysis of wealthy elites, their affiliated philanthropies, and charter school reform in Washington State. Teachers College Record, 116, 080306.

Bae, Y., \& Lee, H. (2012). Sentiment analysis of Twitter audiences: Measuring the positive or negative influence of popular Twitterers. Journal of the American Society for Information Science and Technology, 63(12), 2521-2535.

Bakshy, E., Hofman, J. M., Mason, W. A., \& Watts, D. J. (2011). Everyone's an influencer: Quantifying influence on twitter. Proceedings from 2011 the fourth ACM International Conference on Web Search and Data Mining. New York, NY: ACM.

Batagelj, V., \& Mrvar, A. (2011). Pajek Program for analysis and visualization of large networks. Reference Manual. Retrieved from http://vlado.fmf.uni-lj.si/ pub/networks/pajek/doc/pajekman.pdf.

Borgatti, S. P. (2005). Centrality and network flow. Social Networks, 27, 55-71. 
Borgatti, S. P. (2006). Identifying sets of key players in a network. Computational, Mathematical and Organizational Theory, 12(1), 21-34.

Borgatti, S. P., \& Cross, R. (2003). A relational view of information seeking and learning in social networks. Management Science, 49(4), 432-445.

Borgatti, S. P., \& Everett, M. G. (1992). Notions of position in social network analysis. Sociological Methodology, 22, 1-35.

Burt, R. S. (1976). Positions in networks. Social Forces, 55(1), 93-122.

Burt, R. S. (1999). The social capital of opinion leaders. The Annals of the American Academy of Political and Social Science, 566(1), 37-54.

Burt, R. S. (2005). Brokerage and closure: an introduction to social capital. Oxford, UK: Oxford University Press.

Carpenter, J. P., \& Krutka, D. G. (2014). How and why educators use Twitter: A survey of the field. Journal of Research on Technology in Education, 46(4), 414-434.

Cha, M., Haddadi, H., Benevenuto, F., \& Gummadi, K. P. (2010). Measuring user influence in twitter: The million follower fallacy. Proceedings from 2010 International AAAI Conference on Weblogs and Social Media. Retrieved from http://snap.stanford.edu/class/cs224w-readings/cha10influence.pdf.

Cho, V., Ro, J., \& Littenberg-Tobias, J. (2013). What Twitter will and will not do: Theorizing about teachers' online professional communities. Learning Landscapes, 6(2), 45-62.

Cialdini, R. B., \& Goldstein, N. J. (2004). Social influence: Compliance and conformity. Annual Review of Psychology, 5(1), 591-621.

Coburn, C., \& Russell, J. (2008). Getting the most out of professional learning communities and coaching: Promoting interactions that support instructional improvement. Learning Policy Brief, 1(3), 1-5.

Cole, R. P., \& Weinbaum, E. H. (2010). Changes in attitude: Peer influence in high school reform. In A. J. Daly (Ed.), Social network theory and educational change (pp. 77-96). Cambridge, MA: Harvard University Press.

Cox, D., \& McLeod, S. (2014). Social media marketing and communications strategies for school superintendents. Joumal of Educational Administration, 52(6), 850-868.

Cresci, S., Petrocchi, M., Spognardi, A., Tesconi, M., \& Pietro, R. D. (2014). A criticism to society (as seen by Twitter analytics). Proceedings from IEEE 34 International Conference on Distributed Computing Systems Workshops, Madrid, Spain, 30 June-3 July (pp. 194-200). IEEE Computer Society. Doi: 10.1109/ICDCSW.2014.31

Daly, A. J. (2012). Data, dyads, and dynamics: Exploring data use and social networks in educational improvement. Teachers College Record, 114(11), EJ1001994.

Daly, A. J., \& Finnigan, K. (2012). Exploring the space between: Social networks, trust, and urban school district leaders. Journal of School Leadership, 22(3), 493-530.

Daly, A. J., Liou, Y., Tran, N. A., Cornelissen, F., \& Park. V. (2014). The rise of neurotics: Social networks, leadership, and efficacy in district reform. Educational Administration Quarterly, 50(2), 233-278.

Degenne, A., \& Forse, M. (1999). Introducing social networks. London, UK: Sage. 
Duggan, M. (September 12,2013).It's awoman's (socialmedia) world. Pew Research Center. Retrieved from http://www.pewresearch.org/fact-tank/2013/09/12/ its-a-womans-social-media-world/.

Finnigan, K., \& Daly, A. J. (2012). Mind the gap: Learning, trust, and relationships in an underperforming urban district. American Journal of Education, 119(1), 41-71.

Freeman, L. C. (1977). A set of measures of centrality based upon betweenness. Sociometry, 40, 35-41.

Freeman, L. C. (1979). Centrality in social networks. Conceptual clarification. Social Networks, 1(3), 223-258.

Gruzd, A., \& Wellman, B. (2014). Networked influence in social media: Introduction to the special issue. American Behavioral Scientists, 58(10), 1251-1259.

Haslam, S. A., Reicher, S. D., \& Platow, M. J. (2011). The new psychology of leadership: Identity, influence, and power. NY, NY: Psychology Press.

Herring, S. C., Kouper, I., Scheidt, L. A., \& Wright, E. L. (2004). Women and children last: The discursive construction of weblogs. In L. Gurak, S. Antonijevic, L. Johnson, C. Ratliff, \& J. Reyman (Eds.), Into the Blogosphere: Rhetoric, community, and culture of weblogs. Minneapolis: University of Minnesota. Retrieved from http://blog.lib.umn.edu/blogosphere/women_and_children.html

Huberman, A. B., \& Adamic, L. A. (2004). Information dynamics in the networked world. Lecture notes in Physics, 650, 371-398.

Java, A., Finin, T., Song, X., \& Tseng, B. (2007). Why we Twitter: Understanding microblogging usage and communities. Proceedings of the 9th WebKDD and 1st SNA-KDD workshop on Web mining, San Jose, CA. New York, NY: Association for Computing Machinery.

Junco, R., Heiberger, G., \& Loken, E. (2011). The effect of Twitter on college student engagement and grades. Journal of Computer Assisted Learning, 27(2), 119-132.

Kilduff, M., \& Krackhardt, D. (2008). Interpersonal networks in organizations: Cognition, personality, dynamics, and culture: Structural analysis in the social sciences. New York, NY: Cambridge University Press.

Lin, N. (1976). Foundations of social research. New York, NY: McGraw-Hill.

Lin, N. (2009). Social capital: A theory of social structure and action (8th ed.). New York, NY: Cambridge University Press.

Marques, F., Aquino, J., \& Miola, E. (2014). Congressmen in the age of social network site: Brazilian representatives and Twitter use. First Monday, 19(5). Retrieved from http://firstmonday.org/ojs/index.php/fm/article/view/5022/4084

Moolenaar, N., Daly, A. J., \& Sleegers, P. (2011). Ties with potential: Social network structure and innovation in Dutch schools. Teachers College Record, 113(9), 1983-2017.

Otterbachers, J., Shapiro, M., A., \& Hemphill, L. (2013). Interacting or just acting? A case study of European, Korean, and American politicians? Interactions with the public on Twitter. Journal of Contemporary Easterm Asia, 12(1), 5-20.

Pedersen, S., \& Macafee, C. (2007). Gender differences in British blogging. Journal of Computer-Mediated Communication, 12(4), 1472-1492.

Ratliff, C. (2006). "Where are the women?" Rhetoric and gender in weblog discourse (Unpublished doctoral dissertation). University of Minnesota, Minnesota. 
Raven, B. H., Schwarzwald, J., \& Koslowsky, M. (1998). Conceptualizing and measuring a power/interaction model of interpersonal influence. Joumal of Applied Social Psychology, 28(4), 307-322.

Rogers, E. (2003). Diffusion of innovation (5th ed.). New York, NY: Free Press.

Sabidussi, G. (1966). The centrality index of a graph. Psychometrika, 31, 581-603.

Sauers, N. J., \& Richardson, J. (2015). Learning by following: An analysis of how K-12 school leaders use Twitter. NASSP Bulletin. doi: 10.1177/0192636515583869.

Slaugher, A. J., Yu, J., \& Koehly, L. M. (2009). Social network analysis: Understanding the role of context in small groups and organizations. In E. Salas, G. F. Goodwin \& C. S. Burke (Eds.), Team effectiveness in complex organizations (pp. 433-459). New York, NY: Taylor \& Francis Group.

Stieglitz, S., \& Dang-Xuan, L. (2013). Emotions and information diffusion in social media-sentiment of microblogs and sharing behavior. Journal of Management Information Systems, 29(4), 217-247.

Thackeray, R., Neiger, B. L., Smith, A. K., \& Wagenen, S. B. V. (2012). Adoption and use of social media among public health departments. BMC Public Health, 12(1), 242. Retrieved from http://www.biomedcentral.com/1471-2458/12/242.

Torrente, E., Marti, T., \& Escarrabill, J. (2012). A breath of Twitter. Revista Portuguesa de Pneumonologia, 18(3), 137-141. doi: 10.1016/j.rppneu.2012.02.007.

Twitter.com. (2014a). FAQs about following. Retrieved from https://support.twitter. com/articles/14019-faqs-about-following Twitter.com.(2014b). The Twitter glossary. Retrieved from https://support.twitter.com/groups/50-welcome-to-twitter/ topics/204-the-basics/articles/166337-the-twitter-glossary.

Twitter.com. (2014c). Twitter list. Retrieved from https://support.twitter.com/ articles/76460.

UCEA Center for the Advanced Study of Technology Leadership in Education. (2014). Twitter lists. Retrieved from http://schooltechleadership.org/ socialmedia/.

Veletsianos, G. (2011). Higher education scholars' participation and practices on Twitter. Jourmal of Computer Assisted Learning, 28(4), 336-349.

Wang, Y. (2013). Social media in schools: A treasure trove or hot potato? Journal of Cases in Educational Leadership, 16(1), 83-91.

Wasserman, S., \& Faust, K. (1994). Social network analysis: Methods and applications. New York, NY: Cambridge University Press.

Weng, J., Lim, E., Jiang, J., \& He, Q. (2010). Twitterrank: Finding topic-sensitive influential twitterers. Proceedings of 2010 the third ACM International Conference on Web Search and Data Mining. New York, NY: ACM.

Xu, W. W., Sang, Y., Blasiola, S., \& Park, H. W. (2014). Predicting opinion leaders in Twitter activism networks: The case of the Wisconsin recall election. American Behavioral Scientists, 58(10), 1278-1293.

Zhang, Y., Wu, J., \& Ma, L. (2014). A multi-agent school simulation based hierarchical social networks. Intelligent Information Management, 6, 196-210.

Yinying Wang is an assistant professor of educational leadership in the Department of Educational Policy Studies at College of Education, Georgia State 
University. Her research interest is at the intersection of technology and educational leadership, in particular social media in organizational communication, social media used by the digital public in educational policymaking and implementation, digital inequities in virtual schools, educational technology research collaboration, and open and big data in educational leadership and policymaking.

Nicholas J. Sauers is an assistant professor in the Educational Policy Studies Department at Georgia State University. $\mathrm{He}$ is also an associate director of the Center for the Advanced Study of Technology Leadership in Education. His work focuses on ways that school leaders can enhance their leadership through the use of technology.

Jayson W. Richardson is an associate professor in the Department of Educational Leadership at San Diego State University and a Director of the Center for the Advanced Study of Technology Leadership in Education (CASTLE). His research focuses on technology, leadership, and international development. 
Copyright of Journal of School Leadership is the property of Rowman \& Littlefield Publishers, Inc. and its content may not be copied or emailed to multiple sites or posted to a listserv without the copyright holder's express written permission. However, users may print, download, or email articles for individual use. 